\title{
OC-033 EXTERNAL VALIDATION OF A PROGNOSTIC SCORING SYSTEM FOR PERCUTANEOUS ENDOSCOPIC GASTROSTOMY (PEG)
}

doi:10.1136/gut.2011.239301.33

M Kurien, ${ }^{1}$ H E Robson, ${ }^{1, *}$ J S Leeds, ${ }^{1}$ J Grant, ${ }^{1}$ M E McAlindon, ${ }^{1}$ K L Dear, ${ }^{2}$ B S Hoeroldt, ${ }^{3} \mathrm{~K}$ Kapur, ${ }^{4} \mathrm{G}$ James, ${ }^{5}$ D S Sanders ${ }^{1}{ }^{1}$ Royal Hallamshire Hospital, Sheffield, UK; ${ }^{2}$ Chesterfield Royal Hospital, Chesterfield, UK; ${ }^{3}$ Rotherham District General Hospital, Rotherham, UK; ${ }^{4}$ Barnsley District General Hospital, Barnsley, UK; ${ }^{5}$ Doncaster Royal Infirmary, Doncaster, UK

Introduction There is a significant mortality associated with PEG. The Sheffield Gastrostomy Score (SGS) was devised to try and improve outcomes following this procedure by predicting 30-day mortality. After prospectively collecting demographic, biochemical and outcome data from a cohort of patients having a new PEG inserted (Hospital A, $\mathrm{n}=403)$, multivariate analysis identified that age and albumin were determinants of 30 -day mortality $(p<0.001)$. Age and albumin were attributed scores in a scoring system, the SGS, with age scoring 0 or $1(<65 / \geq 65$ years) and albumin scoring 0,1 or $2(>35,25-34$ and $<25 \mathrm{~g} / \mathrm{L})$. Composite scores in the SGS of 0 to 3 corresponded to 30 -day mortalities of $0 \%, 7 \%, 21.3 \%$ and $37.3 \%$, respectively. The SGS was then validated on a separate cohort of patients from a second hospital in Sheffield, from within the same trust (Internal validation: Hospital B, $\mathrm{n}=153$ ) with comparable 30-day mortality figures. Thus our aim was to externally validate the SGS (outside of Sheffield) and determine its potential application to a wider population.

Methods Four local district general hospitals were used to externally validate the SGS. Demographic, biochemical and outcome data was obtained from all patients undergoing PEG insertion between June 2006 and June 2009. $\chi^{2}$ analysis was used to compare actual 30 -day mortality rates in the external cohort to the rate predicted by the SGS.

Results A total of 679 new PEGs were inserted during this period in these four hospitals. Complete records were obtained from 88\% (597/679) and analysed (median age 71, 322 male). The 30 -day mortality for this external validation cohort was $13.6 \%$. The main indications for PEG insertion were stroke (33.7\%), oropharyngeal malignancy $(32.3 \%)$ and neurodegenerative diseases (17.4\%). Univariate analysis predictors of 30 -day mortality in this external cohort were: increasing age, low serum albumin and stroke. There were no significant differences between the observed and the predicted mortality $(p \geq 0.05)$ in the external validation cohort using the SGS.

Conclusion Our results suggest that the SGS can accurately stratify patients into different risk categories, with higher scores correlating with significantly lower survival. We feel that the SGS could have an important role in those patients where the benefits and risks of gastrostomy are unclear.

Competing interests None.

Keywords percutaneous endoscopic gastrostomy.

Table 1 OC-033 PEG score in internal and external validation cohort

\begin{tabular}{lccc}
\hline Score & $\begin{array}{c}\text { Predicted 30 day } \\
\text { mortality } \\
\text { Hospital A }\end{array}$ & $\begin{array}{c}\text { Internal validation cohort } \\
\text { Hospital B Observed } \\
\text { mortality (p value) }\end{array}$ & $\begin{array}{c}\text { External validation cohort } \\
\text { Observed mortality } \\
\text { (p value) }\end{array}$ \\
\hline 0 & $0 \%$ & $0 \%(1)$ & $3.2 \%(0.57)$ \\
1 & $7 \%$ & $7.7 \%(1)$ & $10.1 \%(0.42)$ \\
2 & $21.30 \%$ & $15.2 \%(0.41)$ & $20.3 \%(0.88)$ \\
3 & $37.30 \%$ & $29.3 \%(0.51)$ & $31.6 \%(0.66)$ \\
\hline
\end{tabular}

